\title{
Resveratrol attenuates malathion-induced renal damage by declining oxidative stress in rats
}

\author{
Cyrus Jalili, Shiva Roshankhah ${ }^{1}$, Yones Moradi ${ }^{1}$, Mohammad Reza Salahshoor ${ }^{1}$ \\ Medical Biology Research Center, Kermanshah University of Medical Sciences, ${ }^{1}$ Department of Anatomical Sciences, Medical School, \\ Kermanshah University of Medical Sciences, Kermanshah, Iran
}

\begin{abstract}
Background: Malathion is the most organophosphates which are capable to produce free radicals and induce disturbance in body antioxidant. Resveratrol is an herbal polyphenol and it has been beneficial antioxidant effects during short-term administration. This study was designed to evaluate the effects of resveratrol against damage induced by malathion to the kidneys of rats.

Materials and Methods: Forty-eight Wistar rats divided randomly into eight groups $(n=6)$ : sham (saline) and malathion control treated groups $(27 \mathrm{mg} / \mathrm{kg})$; resveratrol groups $(2,8$, and $20 \mathrm{mg} / \mathrm{kg}$ ); and resveratrol + malathion-treated groups $(2,8$, and $20 \mathrm{mg} / \mathrm{kg})$. Treatments were administered intraperitoneally and gavage daily for 45 days. Parameters related to the function and the histology of the kidneys were evaluated and statistically analyzed from kidney and blood serum samples in respect of the groups.

Results: Malathion administration increased significantly Bowman's space, qualitative histopathology indices, kidney malondialdehyde (MDA) level, blood urea nitrogen (BUN), creatinine, and nitrite oxide levels and decreased significantly total antioxidant capacity (TAC) level and diameter and number of renal corpuscles compared to the Sham group $(P<0.001)$. The resveratrol and resveratrol + malathion treatments in a dose-dependent manner reduced significantly Bowman's space, qualitative histopathology indices, kidney MDA level, BUN, creatinine, and nitrite oxide levels and increased significantly TAC level and diameter and number of renal corpuscles compared to the malathion control group $(P<0.001)$.

Conclusion: It seems that resveratrol administration in a dose-dependent manner improved kidney injury induced by malathion in rats.
\end{abstract}

Keywords: Malathion, oxidative stress, renal damage, resveratrol

Address for correspondence: Dr. Mohammad Reza Salahshoor, Department of Anatomical Sciences, Medical School, Kermanshah University of Medical Sciences, Kermanshah, Iran.

E-mail: reza.salahshoor@yahoo.com

\section{INTRODUCTION}

Extensive and uncontrolled use of pesticides and insecticides has long been known as a major environmental problem, to which researchers have been trying to discover an appropriate substitute. ${ }^{[1]}$ Organophosphorus compounds

\begin{tabular}{|l|l|}
\hline \multicolumn{2}{|c|}{ Access this article online } \\
\hline Quick Response Code: & Website: \\
\hline & www.jpionline.org \\
\cline { 2 - 2 } & \\
\hline & DOI: \\
\hline
\end{tabular}

are a sanitary problem around the world that has been reported as the third leading cause of toxicity-induced death. ${ }^{[2]}$ Organophosphorus insecticides have phosphor in their structure and are one of the derivatives of phosphoric acid. ${ }^{[3]}$ The most frequently used organophosphorus compounds include metasystox, malathion, xanthion, and

This is an open access journal, and articles are distributed under the terms of the Creative Commons Attribution-NonCommercial-ShareAlike 4.0 License, which allows others to remix, tweak, and build upon the work non-commercially, as long as appropriate credit is given and the new creations are licensed under the identical terms.

For reprints contact: reprints@medknow.com

How to cite this article: Jalili C, Roshankhah S, Moradi Y, Salahshoor MR. Resveratrol attenuates malathion-induced renal damage by declining oxidative stress in rats. Int J Pharma Investig 2018;8:192-9. 
superoxide. ${ }^{[4]}$ The complications of organophosphorus poisoning include cardiac conduction, pulmonary, hepatic, and renal disorders. ${ }^{[5]}$ Malathion is a widely used pesticide belonging to the family of organophosphates. Malathion is a concentrated yellow to dark brown liquid that is widely used as an organic pesticide in agriculture. ${ }^{[6]}$ It is a derivative of dithiophosphoric acid and is a phosphorus pesticide. ${ }^{[7]}$ Various studies have shown that malathion is able to induce oxidative stress in the body. Fortunato et al. showed that malathion could induce the production of free radicals and oxidative stress in the brain and increase the activity of antioxidant enzymes. ${ }^{[8]}$ Further, Al-Othman et al. reported an increase in malondialdehyde (MDA) level and a significant decrease in glutathione and total antioxidant activity in the liver and kidney of rats treated with malathion. ${ }^{\left[{ }^{[9}\right.}$ Increased reactive oxygen species (ROS) can induce oxidative stress and consequently lipid oxidation. ${ }^{[10]}$ Oxidative stress is able to induce DNA failure and inactivation of specific proteins, which is usually followed by the loss of biologic membranes. ${ }^{[11]}$ Free radicals cause lipid peroxidation in the membrane, change enzymatic activity, and induce cell damage and necrosis by attacking unsaturated fatty acids and alkylating the protein groups and other cellular macromolecules. ${ }^{[12]}$ Kidney is the major organ for metabolism and disposal of malathion through urine. ${ }^{[13]}$ The primary or secondary disposal of some drugs and toxins during a progressive trend usually leads to chronic renal disorders. ${ }^{[14]}$ Resveratrol is a plant-derived polyphenolic phytoalexin that is produced by stilbene synthase enzyme in response to environmental stresses such as climate change, exposure to heavy metals, and infectious agents. ${ }^{[15]}$ Grape skin is one of the sources of resveratrol that has 50-100 $\mu \mathrm{g}$ resveratrol per gram of its wet weight. This provides a relatively high concentration of resveratrol in grape juice. ${ }^{[16]}$ Resveratrol has inhibitory effects on free radicals, has antioxidant properties, and increases a number of antioxidative enzymes. The antioxidant effects of this polyphenol depend on the properties of its polyphenolic hydroxyl groups. ${ }^{[17]}$ Resveratrol contains two aromatic groups and, as an antioxidant, inhibits the oxidative stress induced by cell damage and disease. ${ }^{[18]}$ Resveratrol reduces ROS from activated microglial cell lipopolysaccharides by suppressing the activity of nuclear factor-kappa $\beta(\mathrm{NF}-\mathrm{K} \beta)$ and I-K $\beta$ kinase. ${ }^{[19]}$ Malathion has toxic effects, and resveratrol has numerous beneficial properties, especially antioxidant properties. Further, no study has ever investigated the effects of resveratrol on the malathion-induced impairments in the kidney tissue. Hence, the present study was carried out to explore the effects of resveratrol on malathion-induced impairments in the kidney of male rats.

\section{MATERIALS AND METHODS}

\section{Animals}

This experimental study was done from May 2018 to December 2018 on 48 male Wistar rats (weighing 220-250 g) at Kermanshah University of Medical Sciences. All animals were treated in accordance with guidelines of the National Institutes of Health for the care and use of laboratory animals approved by the Research Deputy at Kermanshah University of Medical Sciences based on WMA Declaration Ethic of Helsinki (Ethic number; IR.KUMS.REC.1397.518). The rats were maintained on a regular diet and water ad libitum with a 12:12-h light/dark cycle at $23^{\circ} \mathrm{C} \pm 2{ }^{\circ} \mathrm{C}$ in animal room of medical school of Kermanshah University of Medical Sciences by considering 1 -week adaptation prior to the experiments. ${ }^{[12]}$

\section{Experimental protocol}

The rats were randomly divided into eight groups $(n=6)$, including: first group, the Sham group, which received normal saline (intraperitoneally injection) equivalent to the amount of experimental groups. Second group, the control group of malathion, in this group, the rats were given malathion at a dose of $27 \mathrm{mg} / \mathrm{kg}$ (1/50 LD50) body weight per day (single dose) through gavage (the solvent of malathion was normal saline). Third to fifth groups, the resveratrol administration groups, in these groups, each animal received 2, 8, and $20 \mathrm{mg} / \mathrm{kg}$, respectively, of resveratrol intraperitoneally for 45 days at $10 \mathrm{am}$. Sixth to eighth groups, resveratrol + malathion administration groups, in these groups, each animal received single dose $(27 \mathrm{mg} / \mathrm{kg})$ of malathion through gavage to induce kidney parameter damage, and then, they received 2,8 , and $20 \mathrm{mg} / \mathrm{kg}$, respectively, of resveratrol intraperitoneally for 45 days at $10 \mathrm{am} \cdot{ }^{[6,10]}$

\section{Dissection and sampling}

At the end of the treatment period, all rats were deeply anesthetized by intraperitoneally injection of ketamine $\mathrm{HCl}(100 \mathrm{mg} / \mathrm{kg})$ and xylazine $(10 \mathrm{mg} / \mathrm{kg})$. The sampling included blood from the hearts (at least $1 \mathrm{ml}$ per animal) for evaluating the urea, creatinine, total antioxidant capacity (TAC), and nitrite oxide level. The animals were then sacrificed. The left kidney was removed for histological and morphometric examinations and the right ones for the MDA level estimations, in respect of the groups. ${ }^{[1]}$

The tissue preparing and staining

The nonparenchymal tissues of removed left kidneys were dissected, and the preparing paraffin-embedded blocks were gotten using automatic tissue processor. The steps of this process were consequently included 
fixation with $10 \%$ formal saline, dehydrating by raised a doses of ethanol clearing by xylene, and embedding in soft paraffin $(5-\mu \mathrm{m}$ coronal histological thin sections were cut from paraffin-embedded blocks, undertaken by a microtome instrument, Leica RM2125, Leica Microsystems Nussloch GmbH, Germany), and five sections per animal were chosen. The hematoxylin and eosin staining was implemented. At the end of tissue processing, the stained sections were assessed under Olympus BX-51T-32E01 research microscope connected to a DP12 camera with 3.34-million pixel resolution and Olysia Bio software (Olympus Optical Co., Japan). ${ }^{[10]}$

\section{The histological quantification}

In this study, both qualitative and quantitative histological parameters were evaluated. Qualitative histological involved scoring of the sections by monitoring intracellular vacuolization, tubular dilatation, vascular congestion, intratubular proteinaceous casts, and tubular cell detachments. Quantitative renal tissue changes included estimation of the number and the diameter of renal corpuscles as long as urinary space (Bowman's space) enhancement. For this reason, five sections/animal and five random fields for each section ( 25 fields totally) were captured at $\times 100$ and $\times 400$ magnifications, respectively, by the connected camera to the microscope. The field's selection was done by zigzag form of monitoring of the round or nearly rounded renal corpuscles by a blind observer using a specialized software package (AE-3; Motic S.L.U., Barcelona, Catalonia, Spain), respectively. Briefly, the diameter of each renal corpuscle was estimated as the mean length of two drawing lines, vertical to each other, that connected the distance between opposed basement membranes of the outer cell layer. The Bowman's space, the distance between the outer and the inner cell layers, was estimated by drawing at least four lines (in opposed directions) that connected these two layers, and the mean measured amount of these lines was considered as the space volume. ${ }^{[1]}$

\section{Evaluation of blood urea nitrogen and creatinine}

Blood serum was collected by centrifuging of the samples separately and stored at $-80^{\circ} \mathrm{C}$ until analysis of blood serum urea nitrogen and urine creatinine as two functional universal biomarkers of the kidney. The concentrations of blood urea nitrogen (BUN) and creatinine were analyzed in triplicated with a commercially available assay kit (Bioassay System, USA) in accordance with the instructions. ${ }^{[10]}$

\section{Measurement of renal malondialdehyde}

MDA levels in the right renal tissues were evaluated as an index of lipid peroxidation. In this regard, homogenizing of the samples was carried out by homogenization buffer containing $1.15 \% \mathrm{KCl}$ solution, and the specimens were centrifuged at $1500 \mathrm{~g}$ for $10 \mathrm{~min}$. Then, the homogenated subjects were added to a reaction mixture containing, acetic acid ( $\mathrm{pH} 3.5)$, thiobarbituric acid, and distilled water. Following boiling the mixture for $1 \mathrm{~h}$ at $95^{\circ} \mathrm{C}$ and centrifuging at $3000 \mathrm{~g}$ for $10 \mathrm{~min}$, the absorbency of the supernatant was measured by spectrophotometry at 550 -nm light length. ${ }^{[20]}$

\section{Estimation of renal total antioxidant capacity}

To measure the TAC, an acquisition kit (Cat No: TAC-96A, ZellBio GmbH, Germany) was purchased, which was the basis for the oxidation colorimetry resuscitation. In this assay, the TAC was equivalent to some antioxidant in the sample that was compared with ascorbic acid as standard. The kit's sensitivity was equal to $0.1 \mathrm{mM}$ and final absorbance was read at $490 \mathrm{~nm}$, and unit conversion was performed. ${ }^{[20]}$

\section{Estimation of nitrite oxide levels}

Griess technique uses zinc sulfate powder to eliminate the serum protein of the samples. Accordingly, zinc sulfate powder $(6 \mathrm{mg})$ was mixed with serum samples (400 $\mu \mathrm{l})$ and vortexed for $1 \mathrm{~min}$. The samples were centrifuged at $4^{\circ} \mathrm{C}$ for $10 \mathrm{~min}$ at $12,000 \mathrm{rpm}$, and supernatant was used to measure the nitrite oxide. Briefly, $50 \mu$ of sample was added to $100 \mu \mathrm{l}$ of Griess reagent (Sigma; USA), and the reaction mixture was incubated for about $30 \mathrm{~min}$ at room temperature. According to manufacturer protocol, the sample optical density was measured by enzyme-linked immunosorbent assay reader (Hyperion, USA) at a wavelength of $450 \mathrm{~nm} \cdot{ }^{[21]}$

\section{Statistical analyses}

The Kruskal-Wallis test was used to examine data normality and the homogeneity of variance at a significance level of 0.05 . The data were analyzed by the SPSS software for Windows version 20, (IBM, Chicago, USA) using one-way ANOVA postulation followed by Tukey's post hoc test, and $P<0.05$ was considered statistically significant. The variables were represented as mean \pm standard error of mean.

\section{RESULTS}

Qualitative histopathology changes in treated groups Qualitative histopathology evaluation of renal tissue in the studied groups showed that in malathion control group, a significant increase (with score 31) was observed in all histopathological compared to the normal control group $(P<0.001)$. A significant decrease of these indices was observed in all resveratrol and resveratrol + malathion 
groups compared to malathion control group $(P<0.001)$. Furthermore, there was a dose-dependent significant difference between the resveratrol + malathion groups $(P<0.05)$ [Table 1 and Figure 1].

\section{Number and diameter of renal corpuscles}

Evaluation of the number and diameter of renal corpuscles between the groups showed a significant decrease in the malathion control group compared to the Sham group $(P<0.001)$, but there was no significant difference in resveratrol groups compared to the Sham group. In the all resveratrol and resveratrol + malathion groups, a significant increase in the number and diameter of renal corpuscles was observed in comparison to the malathion control group $(P<0.001)$. Comparing the number and diameter of renal corpuscles between the resveratrol + malathion groups, there was a dose-dependent increase, but these changes were not statistically significant $(P>0.05)$ [Figures 2 and 3].

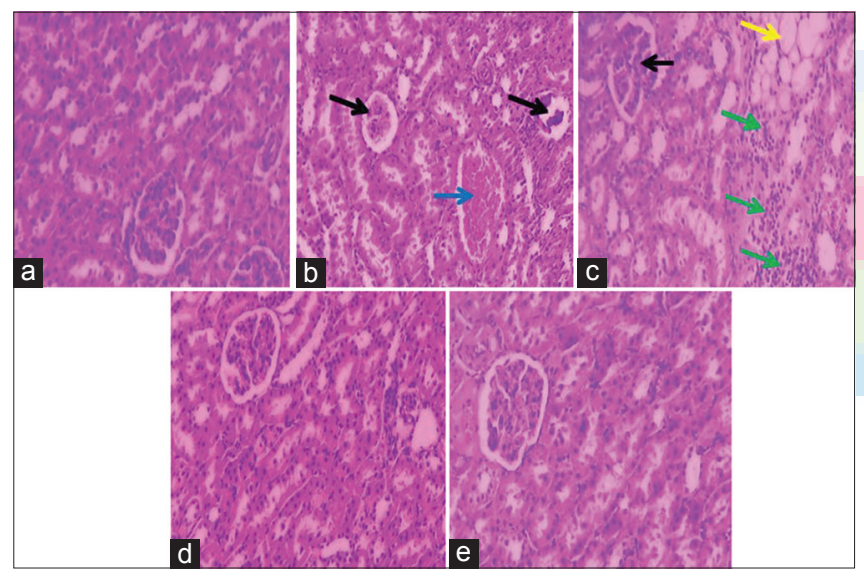

Figure 1: Histological changes in kidneys ( $\mathrm{H}$ and $\mathrm{E}, \times 100)$ : (a) Sham group. (b and c) In these malathion control groups' microscopic pictures, it can be seen increased Bowman's capsule space and glomerular shrinkage (black arrow), distribution of lymphocytes (green arrow), bleeding in the space between the tubules (blue arrow), and formation of adipose tissue (blue arrow). (d) Normal kidney in resveratrol $20 \mathrm{mg} / \mathrm{kg}$ and (e) in malathion + resveratrol $20 \mathrm{mg} / \mathrm{kg}$ group

\section{Bowman's capsule diameter}

The results of the Bowman's capsule diameter showed a significant increase in the malathion control group compared to the Sham group $(P<0.001)$. Further, there was a significant decrease in the resveratrol and resveratrol + malathion groups than the malathion control group $(P<0.001)$ while had no significant effect on the Bowman's capsule diameter in all resveratrol groups compared to the Sham group $(P>0.05)$ [Figure 4].

\section{Measurement serum levels of blood urea nitrogen and creatinine}

Evaluation of serum levels of BUN and creatinine showed a significant increase in the malathion control group compared to the Sham group $(P<0.001)$. A significant decrease in BUN and creatinine levels was showed in all resveratrol and resveratrol + malathion groups compared to the malathion control group $(P<0.001)$ while had no significant effect on the levels of BUN and creatinine in all resveratrol groups compared to the Sham group $(P>0.05)$ [Figure 5].

\section{Malondialdehyde levels}

Serum levels of MDA showed a significant increase in

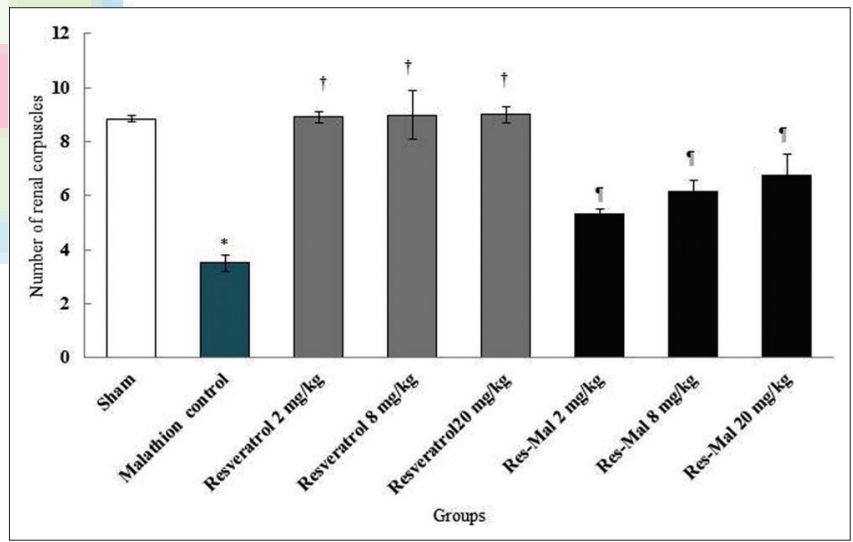

Figure 2: Renal corpuscles' number changes in kidneys. ${ }^{*} P<0.001$ compared to the Sham group. ${ }^{\dagger} P<0.001$ compared to the malathion control group. " $P<0.001$ compared to the malathion control group. Rse: Resveratrol, Mal: Malathion

Table 1: Renal histological qualitative parameters affected by malathion administration and resveratrol treatment and both in male rats

\begin{tabular}{|c|c|c|c|c|c|c|}
\hline \multirow[t]{2}{*}{ Groups } & \multicolumn{6}{|c|}{ Histopathology indices } \\
\hline & $\begin{array}{l}\text { Intracellular } \\
\text { vacuolization }\end{array}$ & $\begin{array}{l}\text { Tubular } \\
\text { dilatation }\end{array}$ & $\begin{array}{l}\text { Vascular } \\
\text { congestion }\end{array}$ & $\begin{array}{c}\text { Intratubular } \\
\text { proteinaceous casts }\end{array}$ & $\begin{array}{l}\text { Tubular cell } \\
\text { detachment }\end{array}$ & Total \\
\hline Sham & 0 & 0 & I & 0 & 0 & 1 \\
\hline Malathion control & IV & IV & IV & $X I I$ & VII & $31^{*}$ \\
\hline Resveratrol 2 & 0 & 0 & 1 & 0 & 0 & $1^{\dagger}$ \\
\hline Resveratrol 8 & 0 & 0 & 1 & 0 & 0 & $1^{\dagger}$ \\
\hline Resveratrol 20 & 0 & 0 & I & 0 & 0 & $1^{\dagger}$ \\
\hline Resveratrol + Malathion 2 & $\|$ & III & IV & III & III & $15^{\pi}$ \\
\hline Resveratrol + Malathion 8 & 0 & $\|$ & $\|$ & 0 & $\|$ & $6^{\pi}$ \\
\hline Resveratrol + Malathion 20 & 0 & 0 & I & 0 & 1 & $2^{\Uparrow}$ \\
\hline
\end{tabular}

${ }^{*} P<0.001$ compared to the Sham group, ${ }^{\dagger} P<0.001$ compared to the malathion control group, " $P<0.001$ compared to the malathion control group 
the malathion control group compared to the Sham group $(P<0.001)$. Furthermore, a significant decrease in MDA levels was showed in all resveratrol and resveratrol + malathion groups compared to the malathion control group $(P<0.001)$ while had no significant effect on the levels of MDA in all resveratrol groups compared to the Sham group $(P>0.05)$ [Figure 6].

\section{Total antioxidant capacity levels}

The results of measured TAC levels in the study groups showed a significant decrease in the malathion control group compared to the Sham group $(P<0.001)$. Furthermore, a significant increase in TAC levels was showed in all resveratrol and resveratrol + malathion groups compared to the malathion control group $(P<0.001)$ while had no significant effect on the levels of TAC in all resveratrol groups compared to the Sham group $(P>0.05)$ [Figure 7].

\section{Nitrite oxide levels}

The mean nitrite oxide in the blood serum increased significantly in the malathion control group compared to the Sham group $(P<0.001)$. The mean nitrite oxide in the blood serum did not change significantly in all resveratrol groups compared to the Sham group $(P>0.05)$. The mean nitrite oxide in the blood serum decreased significantly in all resveratrol and resveratrol + malathion groups compared to the malathion control group $(P<0.001)$ [Figure 8].

\section{DISCUSSION}

The findings of the current research suggested that malathion administration had destructive effects on both histopathology indices and functional parameters of the kidney, oxidant-antioxidant imbalance as well, and increase

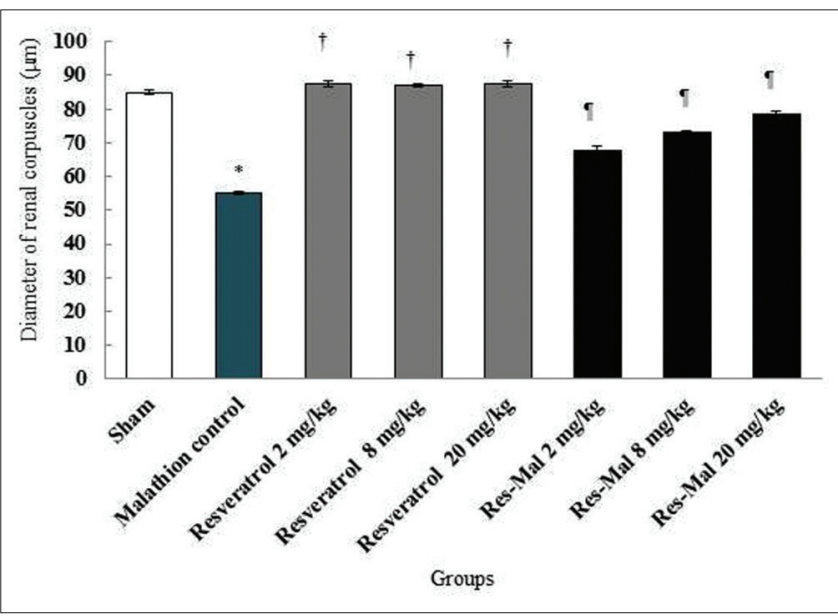

Figure 3: Renal corpuscles' diameter changes in kidneys. ${ }^{*} P<0.001$ compared to the Sham group. ${ }^{\dagger} P<0.001$ compared to the malathion control group. " $P<0.001$ compared to the malathion control group. Rse: Resveratrol, Mal: Malathion in nitrite oxide level. On the other hand, resveratrol as a natural flavonoid decrease the diverse effects of malathion administration. It also recovers the cell damage offering by MDA decreasing and histopathology evaluations and the rate of oxidation (by calculating the amount of TAC). The current study results also showed that resveratrol is able to reduce lipid peroxidation (decreased MDA) and increase antioxidant capacity (increased TAC) of the kidney tissue. Consistent with these findings, a large body of studies has shown antioxidant properties of resveratrol. ${ }^{[10,15,17]}$ Thus, it appears that resveratrol with its antioxidant properties could reduce MDA and increase TAC in the treatment groups by inhibiting the production of reactive oxygen species. The histopathology changes following malathion administration on renal tissue have been approved by some authors, and our results in this regard are parallel with them showing an enlargement of Bowman's space, injury in tubules of the cortex, and occurrence of dramatically change in whole tissue qualitative indices. ${ }^{[6,7]}$ The present study also indicated the recovery effect of resveratrol on renal tissue and on the function of this organ by decreasing the amounts of biochemical markers of renal function. In the present study, the serum nitrite oxide level was significantly higher in the malathion control group than in the Sham group. In all malathion plus resveratrol groups, a significant decrease was observed in serum nitrite oxide compared to the malathion control group. Nitrite oxide is a free radical that is produced in the mammalian cells and interferes with regulation of biologic processes. Administration of malathion can elevate nitrotyrosine and nitrite oxide biomarkers. ${ }^{[2]}$ Nitrotyrosine is known as an inflammatory marker involved in the production of nitrite oxide. ${ }^{[23]}$ Rezvanfar et al. showed that administration of malathion significantly enhanced serum nitrite oxide levels in rats, confirming the results of the present study. ${ }^{[24]}$

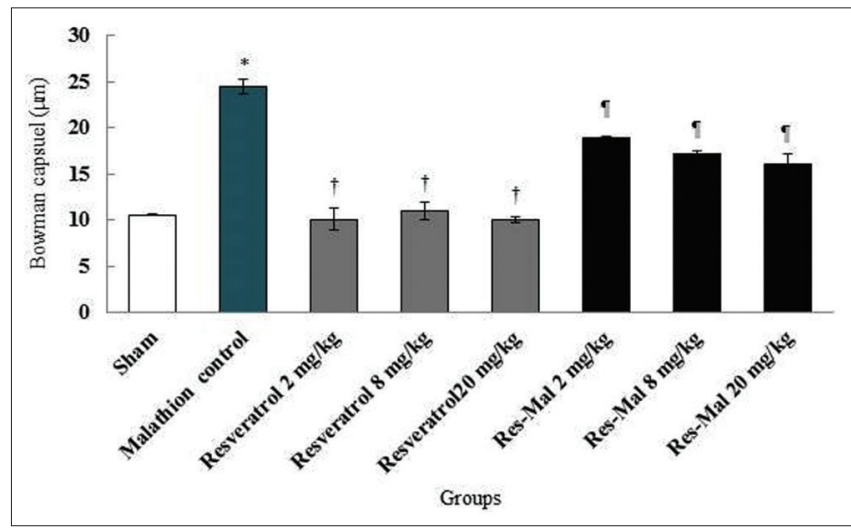

Figure 4: Bowman's capsule changes in kidneys. ${ }^{*} P<0.001$ compared to the Sham group. ${ }^{\dagger} P<0.001$ compared to the malathion control group. " $P<0.001$ compared to the malathion control group. Rse: Resveratrol, Mal: Malathion 


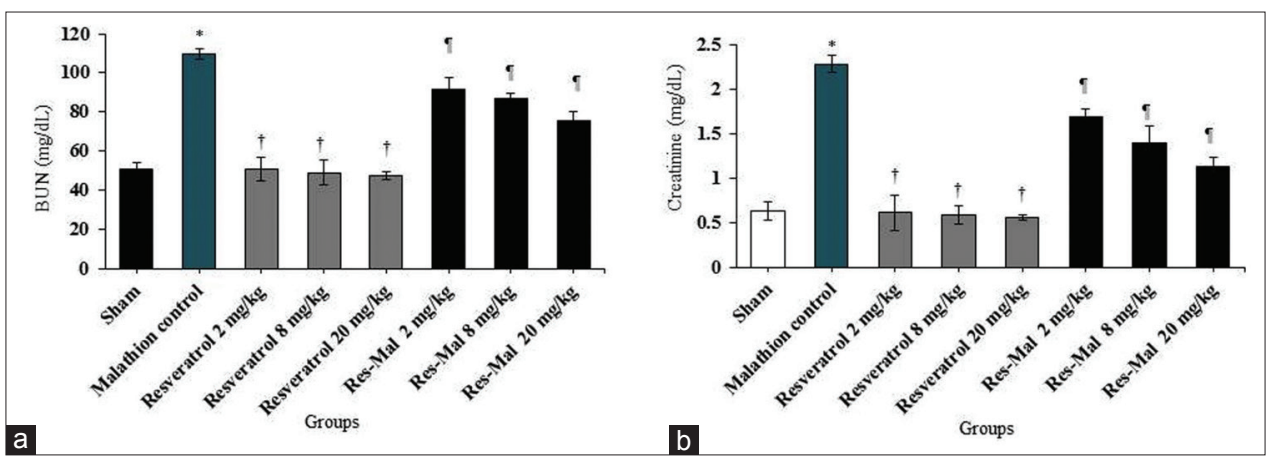

Figure 5: Effect of malathion, resveratrol, and malathion + resveratrol on the mean kidney biochemical factors. (a) Blood urea nitrogen and (b) creatinine. ${ }^{*} P<0.001$ compared to the Sham group. ${ }^{\dagger} P<0.001$ compared to the malathion control group. ${ }^{~} P<0.001$ compared to the malathion control group. BUN: Blood urea nitrogen; Rse: Resveratrol, Mal: Malathion

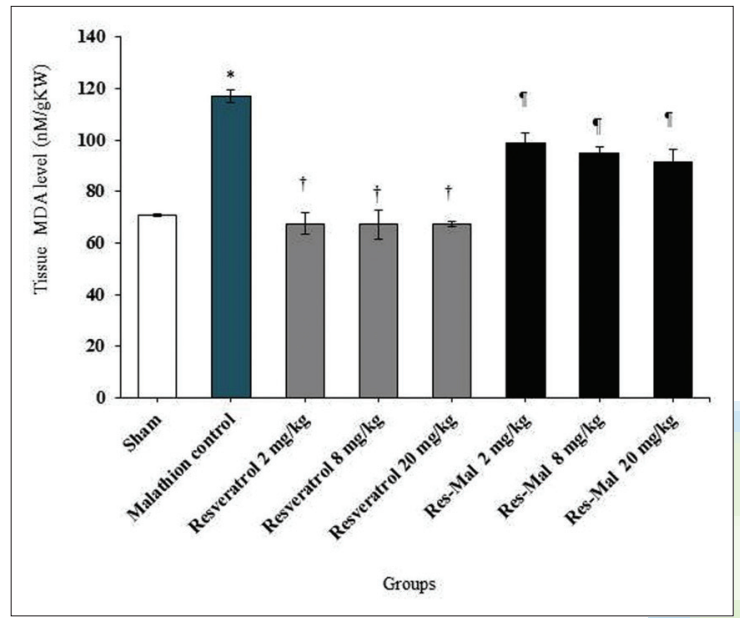

Figure 6: Comparison of malathion, saline, and resveratrol groups of kidney MDA level. ${ }^{*} P<0.001$ compared to the Sham group. ${ }^{\dagger} P<0.001$ compared to the malathion control group." $P<0.001$ compared to the malathion control group. MDA: Malondialdehyde, Rse: Resveratrol, Mal: Malathion

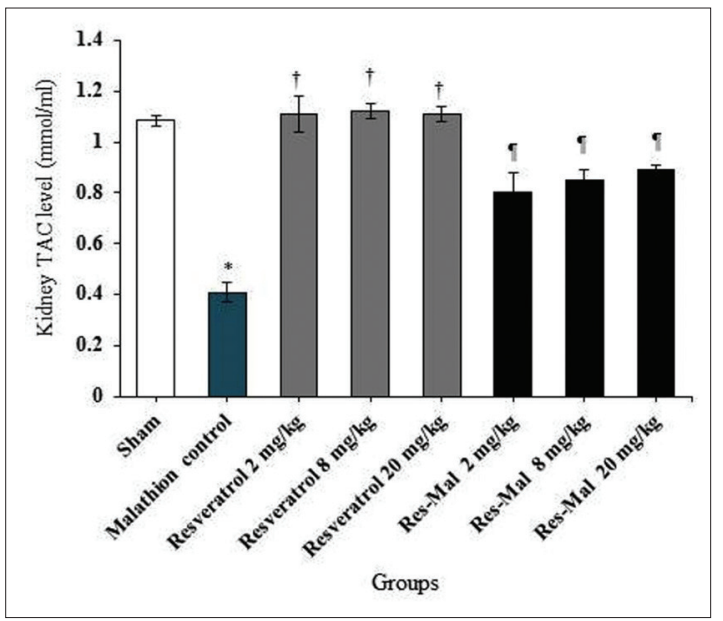

Figure 7: TAC level change in the kidney. ${ }^{*} P<0.001$ compared to the Sham group. ${ }^{\dagger} P<0.001$ compared to the malathion control group. "P $<0.001$ compared to the malathion control group. TAC: Total antioxidant capacity, Rse: Resveratrol, Mal: Malathion

Antioxidants such as resveratrol can destroy and damage the nitrite oxide system (protein enzymes, substrates, and cofactors), thereby decreasing its production. ${ }^{[10]}$ Moreover, the study of Konyalioglu et al. on neural stem cells indicated the same results found in the current study, indicating that resveratrol could significantly reduce nitrite oxide level in stem cells. ${ }^{[25]}$ It seems that resveratrol can decrease nitrite oxide production, induce nitric oxide synthase (NOS) isoforms such as inducible NOS (iNOS), and inhibit the activity of iNOS enzyme by exerting its effects on oxidative and nitrosative stress in microglial cells. ${ }^{[2]]}$ The results of the present study showed that histological damage was followed by a significant decrease in the number and size of glomeruli and a significant increase in glomerular spaces in the malathion control group than in the Sham group. In all malathion plus resveratrol groups, tissue damage repair showed a significant increase in the number and size of glomeruli and a significant decline in the glomerular spaces compared to the malathion control group. Reduced number and mean diameter of glomeruli and increased glomerular space can be followed by functional renal disorders. ${ }^{[11]}$ Therefore, it can be concluded that administration of malathion significantly changes the morphology of renal glomeruli. The membrane of renal cells contains a large amount of unsaturated fatty acids, which can induce lipid peroxidation through the invasion of oxidants. Hence, lipid peroxidation as an oxidant index directly induces cell damage. ${ }^{[27]}$ Seemingly, malathion induces the production of $\mathrm{H}_{2} \mathrm{O}_{2}$ and lipid peroxidation in renal cells, thereby causing histological impairment through DNA breakdown. ${ }^{[6]}$ The frequent malathion-induced histological damages reported in recent studies can be due to the production of oxidative stress and ROS in treatment with malathion. ${ }^{[28]}$ The results of Gupta et al. confirmed the findings of the present study that malathion-induced hepatic damage and cell necrosis. ${ }^{[29]}$ Malathion may exert its biologic effect through an electrophilic attack on the cells in tissues. ${ }^{[30]}$ The protective effects of resveratrol on the kidney in the present study might have been applied through the suppression of expression of NF-K $\beta$ 


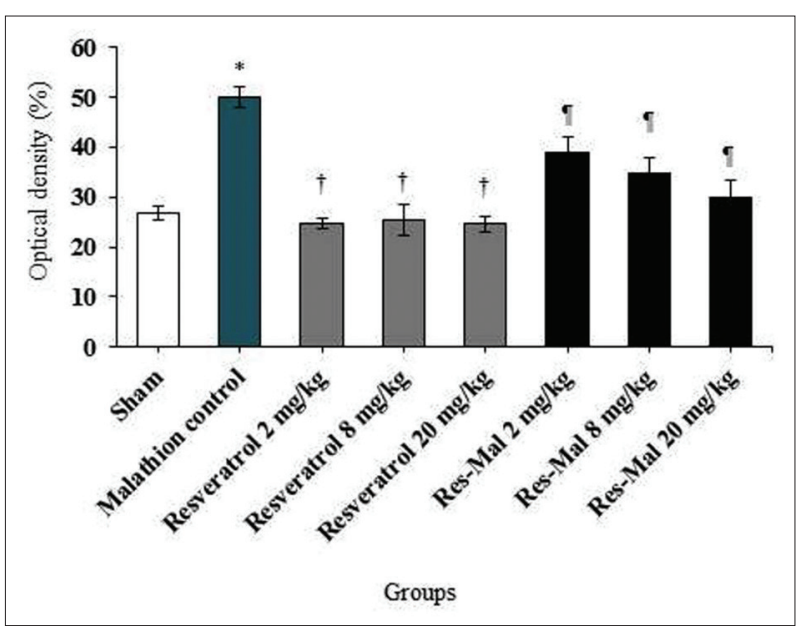

Figure 8: Effects of malathion, resveratrol, and malathion + resveratrol on the mean nitrite oxide levels. ${ }^{*} P<0.001$ compared to the Sham group. ${ }^{\dagger} P<0.001$ compared to the malathion control group. ${ }^{\text {" }} P<0.001$ compared to the malathion control group. Rse: Resveratrol, Mal: Malathion

pathway signals by this material. ${ }^{[31]}$ The findings of Fujii et al. revealed that resveratrol administration reduced the production of ROS and nitrite oxide in proximal tubular cells, which is in line with the results of the current study. ${ }^{[32]}$ Resveratrol appears to exert its anti-inflammatory activities through different ways such as inhibiting the expression of COX1 and COX2 and downregulation of NF-K $\beta$ and I-Kb activities. ${ }^{[33]}$ The increased BUM and creatinine due to malathion administration in the current research are indicative of glomerular damage and can be due to reduced renal excretion of this material. ${ }^{[34]}$ Administration of resveratrol in this study increased the antioxidant level and decreased the BUN and creatinine levels. The findings of Ismail were in agreement with the results of the present study in that malathion administration significantly elevated creatinine and urea levels in male mice. ${ }^{[35]}$ On the other hand, induced oxidative stress and elevated production of free radicals can induce glomerular necrosis and affect the renal filtration capacity. ${ }^{[36]}$ The effects of resveratrol in the recent studies seem to be due to the presence of polyphenol hydroxyl groups in resveratrol, which inhibits the free radicals, provides antioxidant properties, and increases the number of antioxidative enzymes. ${ }^{[37]}$ The findings of Doustar showed that resveratrol caused decreased plasma glucose, creatinine, and oxidative stress in rats, confirming the results of the present research. ${ }^{[38]}$ The present study showed that malathion-induced renal damage in rats could be reduced by plant antioxidants such as resveratrol. Therefore, according to the foregoing, resveratrol can improve renal dysfunction, which has been caused by malathion-induced toxicity considering its antioxidant properties.

\section{CONCLUSION}

The results of this study showed that malathion administration would outbreak dangerous impress from the point of both histology and function. The study approves that eliminated renal oxidant-antioxidant balance as molecular advocator due to the administration of malathion would supervise cellular chain reaction, observable either with light microscopy. Resveratrol, with a dose-dependent manner, upregulates dynamically and improves oxidant system as long as lipid peroxidation following malathion administration. Finally, the antioxidant properties of resveratrol may be the main reason for its positive effect on kidney parameters; however, additional studies are required to define its exact mechanism of action.

\section{Financial support and sponsorship}

This work was conducted in partial fulfillment of the requirements of MD degree of Yones Moradi which was financially (Grant No. 1397.518) supported by the Research Council of Kermanshah University of Medical Sciences, Kermanshah, Iran.

\section{Conflicts of interest}

There are no conflicts of interest.

\section{REFERENCES}

1. Fernandes FO, Abreu JA, Christ LM, Rosa AP. Efficacy of insecticides against Spodoptera frugiperda (Smith, 1797). J Agric Sci 2019;11:494-503.

2. Beser MI, Pardo O, Beltrán J, Yusà V. Determination of 21 perfluoroalkyl substances and organophosphorus compounds in breast milk by liquid chromatography coupled to orbitrap high-resolution mass spectrometry. J Agric Sci 2019;1049:123-32.

3. Yoshifuji M. Low-coordinate organophosphorus compounds: Some stereochemical considerations. Pure Appl Chem 2019;91:77-85.

4. Lukaszewicz-Hussain A. Role of oxidative stress in organophosphate insecticide toxicity - Short review. Pest Biochem Physiol 2010;98:145-50.

5. Naik KR, Saroja AO, Hesarur N, Patil RS. Prospective hospital-based clinical and electrophysiological evaluation of acute organophosphate poisoning. Ann Indian Acad Neurol 2019;22:91-5.

6. Madzorera T, Sibanda M, Focke W, Madito M, Manyala N. Malathion-filled trilayer polyolefin film for malaria vector control. Mater Sci Eng C Mater Biol Appl 2019;96:419-25.

7. Khoei AJ, Joogh NJ, Darvishi P, Rezaei K. Application of physical and biological methods to remove heavy metal, arsenic and pesticides, malathion and diazinon from water. Turk J Fish Aquat Sci 2019;19:21-8.

8. Fortunato JJ, Feier G, Vitali AM, Petronilho FC, Dal-Pizzol F, Quevedo J. Malathion-induced oxidative stress in rat brain regions. Neurochem Res 2006;31:671-8.

9. Al-Othman AM, Al-Numair KS, El-Desoky GE, Yusuf K, Al Othman ZA, Aboul-Soud MA, et al. Protection of-tocopherol and selenium against acute effects of malathion on liver and kidney of rats. Afr J Pharm Pharmacol 2011;5:1263-71.

10. Jalili C, Makalani F, Roshankhah S, Sohrabi K, Salahshoor MR. Protective effect of resveratrol against morphine damage to kidneys of mice. Int J Morphol 2017;35:1409-15.

11. Jalili C, Salahshoor MR, Hoseini M, Roshankhah S, Sohrabi M, Shabanizadeh A. Protective effect of thymoquinone against morphine 
injuries to kidneys of mice. Iran J Kidney Dis 2017;11:142-50.

12. Salahshoor MR, Vahabi A, Roshankhah S, Darehdori AS, Jalili C. The effects of thymoquinone against morphine-induced damages on male mice liver. Int J Prev Med 2018;9:8.

13. Selmi S, Rtibi K, Grami D, Sebai H, Marzouki L. Malathion, an organophosphate insecticide, provokes metabolic, histopathologic and molecular disorders in liver and kidney in prepubertal male mice. Toxicol Rep 2018;5:189-95.

14. Garlo KG, Steele DJ, Nigwekar SU, Chan KE. Demystifying the benefits and harms of anticoagulation for atrial fibrillation in chronic kidney disease. Clin J Am Soc Nephrol 2019;14:125-36.

15. Jalili C, Salahshoor MR, Jalili F, Kakaberaei S, Akrami A, Sohrabi M, et al. Therapeutic effect of resveratrol on morphine-induced damage in male reproductive system of mice by reducing nitric oxide serum level. Int J Morphol 2017;35:1342-7.

16. Baliga MS, Meleth S, Katiyar SK. Growth inhibitory and antimetastatic effect of green tea polyphenols on metastasis-specific mouse mammary carcinoma 4T1 cells in vitro and in vivo systems. Clin Cancer Res 2005;11:1918-27.

17. Cucciolla V, Borriello A, Oliva A, Galletti P, Zappia V, Della Ragione F, et al. Resveratrol: From basic science to the clinic. Cell Cycle 2007;6:2495-510.

18. King RE, Bomser JA, Min DB. Bioactivity of resveratrol. Compr Rev Food Sci Food Saf 2006;5:65-70.

19. Udenigwe CC, Ramprasath VR, Aluko RE, Jones PJ. Potential of resveratrol in anticancer and anti-inflammatory therapy. Nutr Rev 2008; $66: 445-54$

20. Badehnoosh B, Karamali M, Zarrati M, Jamilian M, Bahmani F, Tajabadi-Ebrahimi M, et al. The effects of probiotic supplementation on biomarkers of inflammation, oxidative stress and pregnancy outcomes in gestational diabetes. J Matern Fetal Neonatal Med 2018;31:1128-36.

21. Salahshoor MR, Roshankhah S, Hosseni P, Jalili C. Genistein improves liver damage in male mice exposed to morphine. Chin Med J (Engl) 2018;131:1598-604.

22. Selmi S, El-Fazaa S, Gharbi N. Oxidative stress and alteration of biochemical markers in liver and kidney by malathion in rat pups. Toxicol Ind Health 2015;31:783-8.

23. Paul KC, Sinsheimer JS, Rhodes SL, Cockburn M, Bronstein J, Ritz B. Organophosphate pesticide exposures, nitric oxide synthase gene variants, and gene-pesticide interactions in a case-control study of Parkinson's disease, California (USA). Environ Health Perspect 2016;124:570-7.

24. Rezvanfar MA, Rezvanfar MA, Ranjbar A, Baeeri M, Mohammadirad A, Abdollahi M. Biochemical evidence on positive effects of rolipram a phosphodiesterase-4 inhibitor in malathion-induced toxic stress in rat blood and brain mitochondria. Pest Biochem Physiol 2010;98:135-43.

25. Konyalioglu S, Armagan G, Yalcin A, Atalayin C, Dagci T. Effects of resveratrol on hydrogen peroxide-induced oxidative stress in embryonic neural stem cells. Neural Regen Res 2013;8:485-95.

26. de la Lastra CA, Villegas I. Resveratrol as an antioxidant and pro-oxidant agent: Mechanisms and clinical implications. Biochem Soc Trans 2007;35:1156-60.

27. Lurie E, Soloviova A, Alyabieva T, Kaplun A, Panchenko L, Shvets V. Effect of novel aromatic derivative of GABA on lipid peroxidation in chronically morphinized rats. Biochem Mol Biol Int 1995;36:13-9.

28. Bagchi D, Bagchi M, Hassoun EA, Stohs SJ. In vitro and in vivo generation of reactive oxygen species, DNA damage and lactate dehydrogenase leakage by selected pesticides. Toxicology 1995;104:129-40.

29. Gupta RC, Singh N, Paul BS, Kwatra MS. Role of residual estimation and clinico-biochemical and pathological changes in the diagnosis of toxicity in Bubalus bubalis caused by malathion. Indian J Anim Sci 1981;51:616-22.

30. Ouardi FZ, Anarghou H, Malqui H, Ouasmi N, Chigr M, Najimi M, et al. Gestational and lactational exposure to malathion affects antioxidant status and neurobehavior in mice pups and offspring. J Mol Neurosci 2019;12:1-11.

31. Pan QR, Ren YL, Zhu JJ, Hu YJ, Zheng JS, Fan H, et al. Resveratrol increases nephrin and podocin expression and alleviates renal damage in rats fed a high-fat diet. Nutrients 2014;6:2619-31.

32. Fujii H, Yokozawa T, Kim YA, Tohda C, Nonaka G. Protective effect of grape seed polyphenols against high glucose-induced oxidative stress. Biosci Biotechnol Biochem 2006;70:2104-11.

33. Kim YA, Kim GY, Park KY, Choi YH. Resveratrol inhibits nitric oxide and prostaglandin E2 production by lipopolysaccharide-activated C6 microglia. J Med Food 2007;10:218-24.

34. Subburaj A, Jawahar P, Jayakumar N, Srinivasan A, Ahilan B. Histopathological investigations in liver and kidney of the fish, Oreochromis mossambicus (Tilapia) exposed to acute malathion (EC 50\%) toxicity. Biosci Biotechnol Biochem 2018;21:77-81.

35. Ismail SM. Protective effects of Vitamin $C$ against biochemical toxicity induced by malathion pesticides in male albino rat. J Evol Biol 2013;5:1-5.

36. Izol V, Arıdoğan IA, Tansuğ Z, Doran F, Erdoğan KE, Kaplan HM, et al. Hypericum perforatum extract against oxidative stress, apoptosis and oedema in kidney induced by gentamicin. Int J Pharmacol 2019;15:66-73.

37. Ghanim H, Sia CL, Abuaysheh S, Korzeniewski K, Patnaik P, Marumganti A, et al. An antiinflammatory and reactive oxygen species suppressive effects of an extract of polygonum cuspidatum containing resveratrol. J Clin Endocrinol Metab 2010;95:E1-8.

38. Doustar Y. Resveratrol attenuates nephropathy in streptozotocin-induced diabetic rats. Life Sci 2013;10:167-71. 